\title{
INJÚRIA POTENCIAL DE HERBICIDAS DE SOLO AO GIRASSOL. IV - Rendimento de aquênios e componentes do rendimento
}

\author{
RIBAS A. VIDAL ${ }^{2}$ e NILSON G. FLECKS ${ }^{3}$
}

\begin{abstract}
RESUMO
Conduziu-se um ensaio em campo na Estação Experimental Agronômica da Universidade Federal do Rio Grande do Sul, em Eldorado do Sul, RS, em 1989/90. O objetivo foi determinar o efeito dos herbicidas clomazone, chlorimuronethyl, imazaquin e imazethaphyr, aplicados em três doses à superfície do solo (PRE) ou incorporados no mesmo (PPI), sobre o rendimento de aquênios de girassol e seus componentes. Os herbicidas de solo para controle de plantas daninhas na cultura da soja com maior potencial de dano ao

girassol cultivado em sucessão, conforme indicado pelo rendimento de aquênios, foram os seguintes, em ordem decrescente: imazaquin > clomazone > imazethapyr > chlorimuron-ethyl. $\mathrm{O}$ efeito mais pronunciado dos herbicidas foi a redução da população de plantas. Este foi o fator que mais influenciou no rendimento do girassol.

Palavras-chave: Helianthus annuus, herbicidas residuais, dissipação de herbicidas, persistência no solo, rotação de culturas, soja.
\end{abstract}

\section{ABSTRACT \\ Potential sunflower injury by soil applied herbicides. IV - Achene yield and yield components}

A field experiment was carried-out during 1989/90 at the Eldorado do Sul Experimental Station of Federal University of "Rio Grande do Sul", Brazil, with the objective of evaluating the effect of clomazone, chlorimuron-ethyl, imazaquin and imazethapyr applied at three different dosages in pre-emergence (PRE) or preplant incorporated (PPI), on sunflower achene yield and its components. Herbicide injury potential, as indicated by sunflower yield, was the

\section{INTRODUÇÃO}

Uma preocupação dos agricultores que praticam a rotação soja-girassol é a possibilidade de persistência de herbicidas, utilizados na lavoura de soja, na cultura de giras- following, from more to less phytotoxic: imazaquin > clomazone > imazethapyr > chlorimuron-ethyl. The main effect of the herbicides was in sunflower stand reduction, and this was the main yield component which was affected.

Additional index words: Helianthus annuus, resídual herbicide, herbicide dissipation, soil persistence, crop rotation, soybean.

sol. Como o intervalo entre a semeadura da soj a e a do girassol varia de 7 a 10 meses, dependendo das condições ambientais, poderiam ocorrer sintomas de intoxicação na cultura de girassol devido à persistência dos herbicidas com ação através do solo (Vranceanu, 1977; Wilkins \& Swallers, 1972; Fleck, 1990).

1 Recebido para publicação em 06/04/93 e na forma revisada em 12/02/94.

Extraído da Dissertação apresentada pelo primeiro autor para obtenção do grau de Mestre em Fitotecnia pela Fac. de Agron. da Univ. Fed. do Rio Grande do Sul (UFRS), Porto Alegre, RS. Trabalho parcialmente financiado pelo CNPq (Processo n $\left.{ }^{\circ} 414024 / 89-3 / A G\right)$.

2 Eng $^{\circ}$ Agr $^{\circ}$, MSc, Prof. Assist., Dep. de Plantas de Lavoura, Fac. de Agron., UFRS, Av. B. Gonçalves, 7712, Caixa Postal 776, CEP 90001-000 Porto Alegre, RS.

3 Eng $^{\circ}$ Agr $^{\circ}, \mathrm{PhD}$, Prof. Adjunto, Bolsista do CNPq, Dep. de Plantas de Lavoura, Faculdade de Agronomia, UFRS. 
Nos últimos anos, diversos herbicidas foram desenvolvidos para a cultura da soja. Entre estes produtos encontramse os dos grupos químicos: imidazolinonas, isoxazolidinonas e sulfoniluréias. Todos os produtos destes grupos químicos têm, como característica comum, a persistência relativamente longa no solo, e esta é influenciada pelos seguintes fatores: decomposição química, adsorção aos colóides do solo, lixiviação, volatilização, fotodecomposição, absorção e metabolização pelas plantas e/ou microorganismos (Beckie \& McKercher, 1989; Gallandt et al., 1989; Witt, 1989).

A persistência de herbicidas no solo precisa ser devidamente equacionada, pois dependendo do produto e da espécie vegetal em questão, os sintomas de intoxicação observados nas plântulas podem desaparecer com o desenvolvimento do vegetal, chegando ao ponto de não se observar queda no rendimento final (Cu rran \& Knake, 1987; Snipes \& Street, 1987; Renner et al., 1988; Gallandt et al., 1989; Eberlein et al., 1989; Griffin \& Baker, 1990). Por outro lado, pode ocorrer o efeito contrário, isto é, inicialmente os sintomas são pouco pronunciados e, com o decorrer do tempo, eles se acentuem de tal forma que, no final do ciclo da cultura, o rendimento fique minimizado (Brewster \& Appleby, 1983; Peterson \& Arnold, 1985).

O objetivo deste trabalho foi determinar o efeito de clomazone, chlorimuron-ethyl, imazaquin e imazethapyr, aplicados ao solo, sobre o rendimento de aquênios e seus componentes na cultura do girassol, visando ao sistema de rotação com a cultura de soja.

\section{MATERIAL E MÉTODOS}

O experimento foi conduzido a campo durante a estação de crescimento 1989/90, na Estação Experimental Agronômica (EEA) da Universidade Federal do Rio Grande do Sul (UFRS), localizada no município de Eldorado do Sul, RS, região fisiográfica da Depressão Central do Estado.

O delíneamento experimental utilizado foi o de blocos casualizados, com os tratamentos arranjados em parcelas subdivididas, com quatro repetições. Cada bloco foi composto de duas parcelas às quais foram destinadas as épocas de aplicação dos herbicidas [pré-plantio incorporado (PPI) e pré-emergência (PRE)]. Cada parcela foi dividida em 12 unidades experimentais (subparcelas) nas quais foram aplicados, de forma aleatória, os tratamentos herbicidas. A área total da parcela foi de $120 \mathrm{~m}^{2}$ (4 x 30m); a da subparcela foi de $10 \mathrm{~m}^{2}(2,5 \mathrm{x} 4 \mathrm{~m})$, com uma área útil central de 4,5 $\mathrm{m}^{2}(1,5$ x $3 \mathrm{~m})$. A cada bloco acrescentou-se uma área extra de $10 \mathrm{~m}^{2}$ $(2,5 \times 4 \mathrm{~m})$, destinada à testemunha não tratada com herbicida de solo. Cada repetição apresentou, portanto, 25 unidades experimentais (subparcelas).

Em cada época de aplicação (parcela) os tratamentos foram organizados num esquema fatorial hierárquico, isto é, foram utilizados os seguintes herbicidas com as respectivas doses: 1000,500 e $100 \mathrm{~g} /$ ha de clomazone; 50, 25 e $5 \mathrm{~g} / \mathrm{ha}$ de chlorimuron; 150,75 e $15 \mathrm{~g} / \mathrm{ha}$ de imazaquin; e 100,50 e 10 $\mathrm{g} /$ ha de imazethapyr. Estas doses corresponderam àquelas usuais, meio e um décimo daquelas recomendadas pela pesquisa para utilização em soja.
As informações quanto ao tipo de solo, preparo e adubação do mesmo, aplicações dos herbicidas, semeadura do girassol e tratos culturais foram as descritas por Vidal \& Fleck (1994).

Durante os 40 dias após a aplicação dos herbicidas ocorreram precipitações pluviais da ordem de $270 \mathrm{~mm}$.

Aos 110 dias após a semeadura, quando as plantas se encontravam no estádio $\mathrm{R}_{8}$, determinourse o diâmetro médio do capítulo, avaliando-se dez plantas por subparcela.

Por ocasião da colheita, realizada 147 dias após a semeadura, determinaram-se o número de plantas por área, o rendimento de aquênios, o peso de 1000 aquénios e o número de aquênios por capítulo. Para se determinar o número de plantas por hectare foi considerado o número de capítulos colhidos na área útil da subparcela. $\mathrm{O}$ rendimento de aquênios, expresso em quilogramas por hectare, foi determinado após a pesagem dos aquênios colhidos na área útil, depois de determinada a umidade neles contida e corrigido o peso para $10 \%$ de umidade. O grau de umidade foi estimado por uma amostragem de $100 \mathrm{~g}$ de aquênios, os quais foram levados à estufa com circulação de ar e mantidos a $60^{\circ} \mathrm{C}$ por um período de 120 horas, após o qual, novamente se determinou seu peso. O peso de 1000 aquênios foi obtido através da pesagem de uma amostra de 500 aquénios previamente secos (10\% de umidade). O número de aquênios por capítulo foi avaliado pela equação (Vidal, 1990):

$$
\mathrm{NAC}=(1000 * \mathrm{PTA}) /(\mathrm{PMA} * \mathrm{NC})
$$

onde NAC correspondeu ao número de aquênios por capítulo, PTA ao peso total de aquênios colhidos (g/ha), PMA ao peso de 1000 aquênios (g), e NC ao número de capítulos colhidos por hectare.

As variáveis avaliadas no experimento foram submetidas à análise de variância de acordo com o modelo de parcelas subdivididas. Quando constatada a significância de dose de herbicida ou da interação época de aplicação*dose dos mesmos, procedeu-se ao desdobramento dos graus de liberdade correspondentes, utilizando-se a análise de regressão, testando-se a significância da regressão linear e desvios da mesma. Os coeficientes polinomiais ortogonais foram calculados através do método para níveis não-equidistantes, desenvolvido por Nogueira (1979). Determinaram-se as equações lineares significativas e, caso o quadrado médio dos desvios de uma regressão tenha sido significativo, utilizou-se o procedimento apresentado por Gomez \& Gomez (1984).

Cada dose herbicida foi comparada à testemunha (sem aplicação) através do teste DMS, ao nível de 5\% de probabilidade. Optou-se pela utilização do teste DMS, neste experimento, principalmente para comparar a testemunha com a menor dose testada, uma vez que a análise de regressão já é suficiente para a comparação entre as doses (Chew, 1976 e Petersen, 1977).

Calcularam-se as equações de regressão linear (múltipla e simples) do rendimento e componentes, sendo determinada a significância dos coeficientes de cada parâmetro pelo teste $\mathrm{T}$, ao nível de $5 \%$ de probabilidade. 


\section{RESULTADOS E DISCUSSÃO}

O número de plantas por hectare, avaliado na época da colheita, encontra-se na Figura 1. Verificou-se interação de épocas de aplicação e doses de chlorimuron-ethyl. Tal fato oco rreu porque o chlorimuron-ethyl, ao ser aplicado em PRE, não afetou o número de plantas na área com o incremento da dose; no entanto, quando aplicado em PPI, ocasionou redução linear do número de plantas com o incremento da dose do herbicida.

Observou-se também efeito linear na redução de plantas com o aumento da dose de clomazone, imazaquin e imazethapyr. No caso de ímazaquin, houve eliminação das plantas de girassol em todas as parcelas onde se empregou a maior dose; enquanto que, este mesmo produto, utilizado na dose intermediária, e clomazone na maior dose, eliminaram 62 e $75 \%$ das plantas, respectivamente.

Nenhum dos herbicidas, utilizados na menor dose, reduziu o número de plantas de girassol, quando comparados à testemunha (Figura 1).

Constatou-se redução no diâmetro de capítulo somente quando as plantas se desenvolveram em área tratada com imazaquin. Esta redução se deu de forma linear com o incremento da dose (Figura 2). Não foi constatada influência das épocas de aplicação nem interação destas com as doses dos herbicidas. Da mesma forma, em nenhum tratamento herbicida o diâmetro de capítulo das plantas que se desenvolve ram na área tratada com a menor dose diferiu daquele observado na testemunha (Figura 2).

A análise de variância do peso de mil aquênios também não evidenciou efeito entre épocas de aplicação e doses de imazaquin (Figura 3). Com o aumento da dose de imazaquin, constatou-se redução linear do peso médio do aquênio. Este fato se deveu ao efeito da eliminação de plantas nas parcelas com as maiores doses deste herbicida. Verificou-se também resposta linear desta variável com o incremento de doses de clomazone. Já o incremento das doses de chlorimuron-ethyl e imazethapyr não resultaram em diferenças da variável. Tampouco as comparações entre a menor dose dos herbicidas testados e a testemunha indicaram diferenças significativas (Figura 3).

O número de aquênios por capítulo está apresentado graficamente na Figura 4. Este componente não foi influenciado pelas épocas de aplicação. As comparações entre a testemunha e as menores doses dos herbicidas testados não evidenciaram diferenças significativas, indicando que as mesmas não afetaram o número de aquênios por capítulo. Contudo, constatou-se que, com o incremento da dose de imazaquin, houve redução linear do número de aquênios por capítulo. Todavia, nos demais tratamentos herbicidas não se verificou resposta significativa deste parâmetro com o aumento da dose (Figura 4).

$\mathrm{Na}$ avaliação de rendimento de aquênios, a interação de épocas de aplicação e doses de chlorimuron-ethyl foi significativa (Figura 5). Observa-se que em PPI a menor

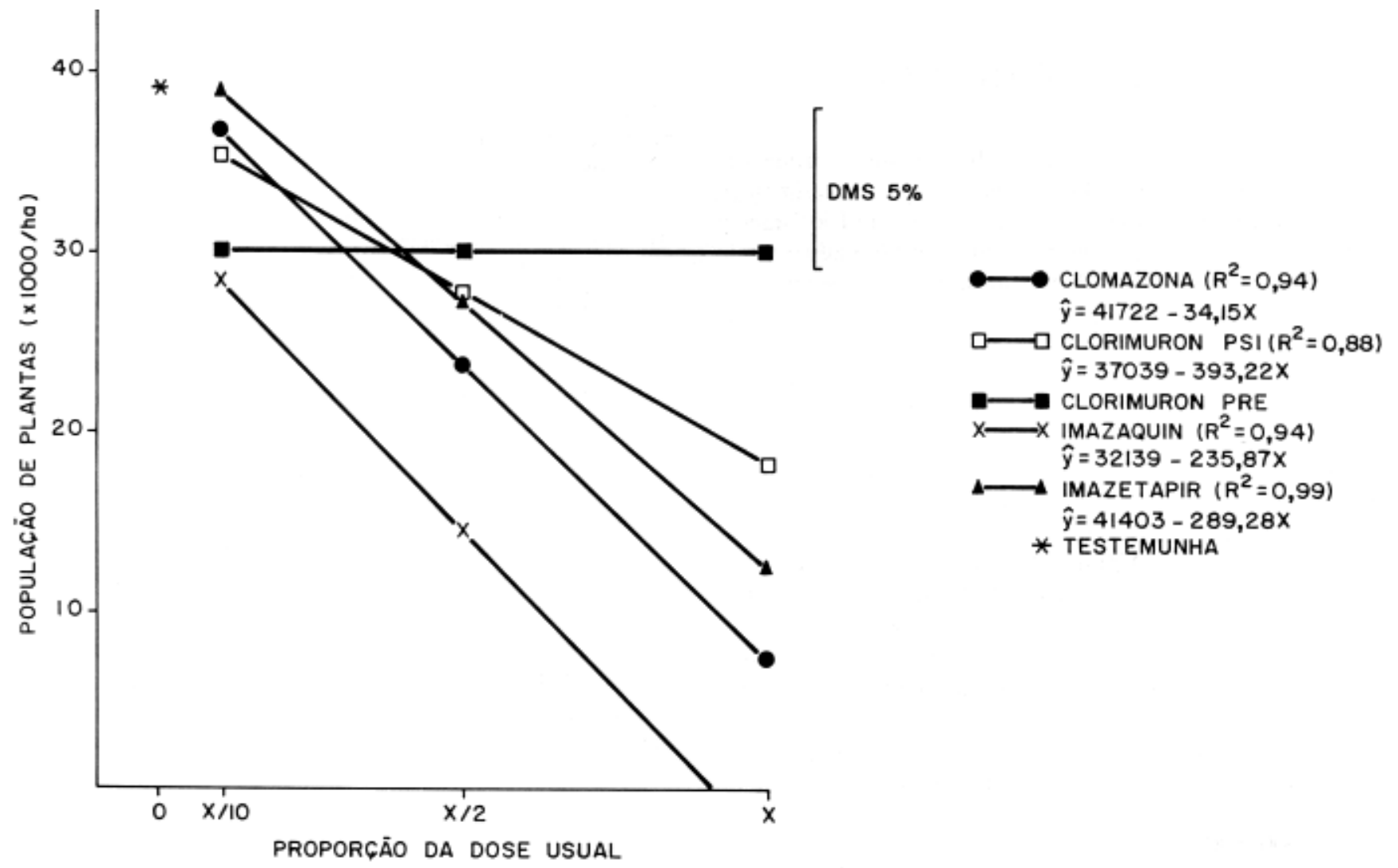

FIG. 1 - População de plantas de girassol na colheita, após aplicação ao solo dos herbicidas clomazone, chlorimuronethyl, imazaquin e imazethapyr, comparados à testemunha sem herbicidas. EEA/UFRS, Eldorado do Sul, RS, 1989/90. 


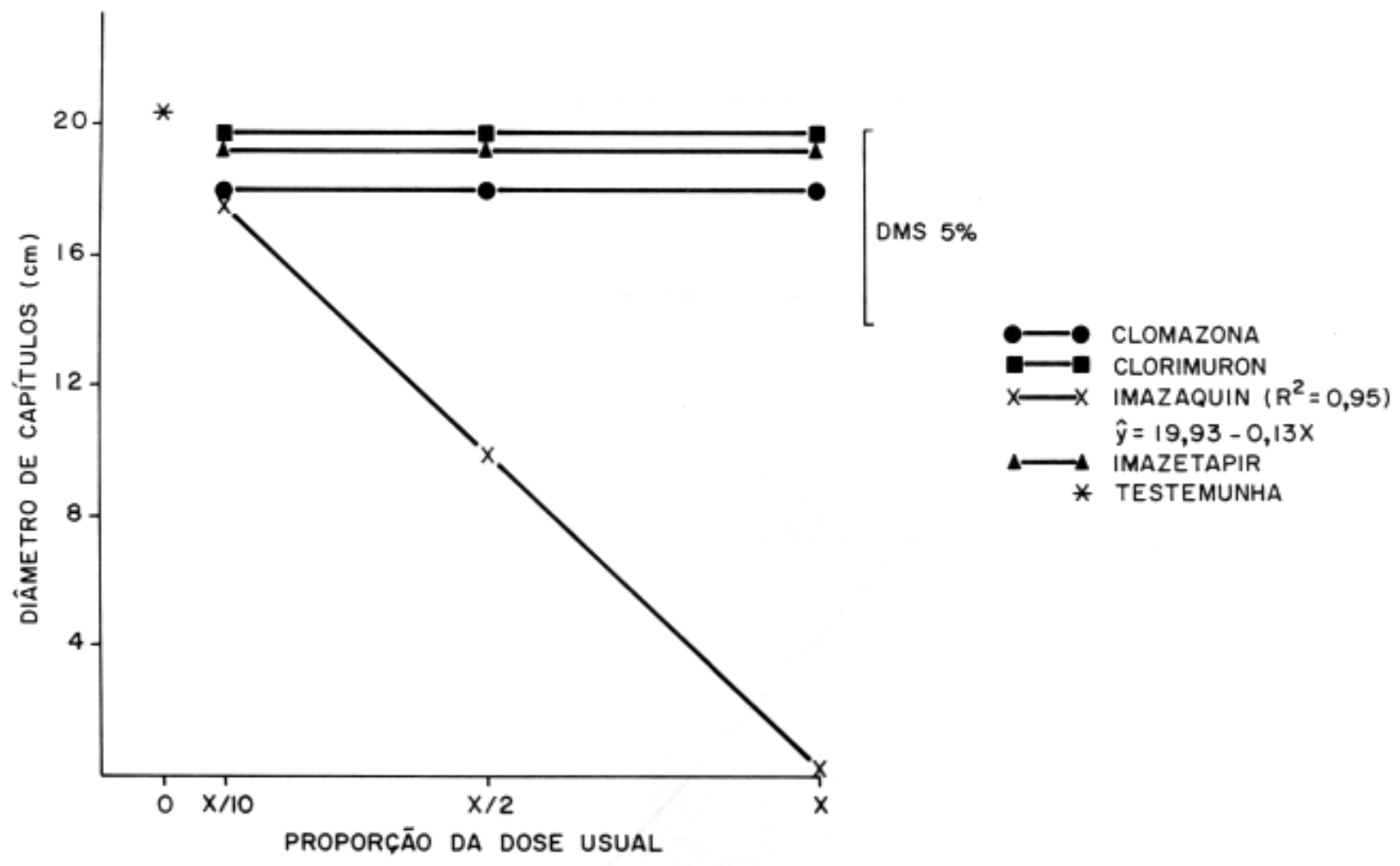

FIG. 2 - Diâmetro de capítulos de girassol (cm), na média de duas épocas de aplicação, aos 110 dias após aplicação ao solo dos herbicidas clomazone, chlorimuron-ethyl, imazaquin e imazethapyr, comparados à testemunha sem herbicidas. EEA/UFRS, Eldorado do Sul, RS, 1989/90.

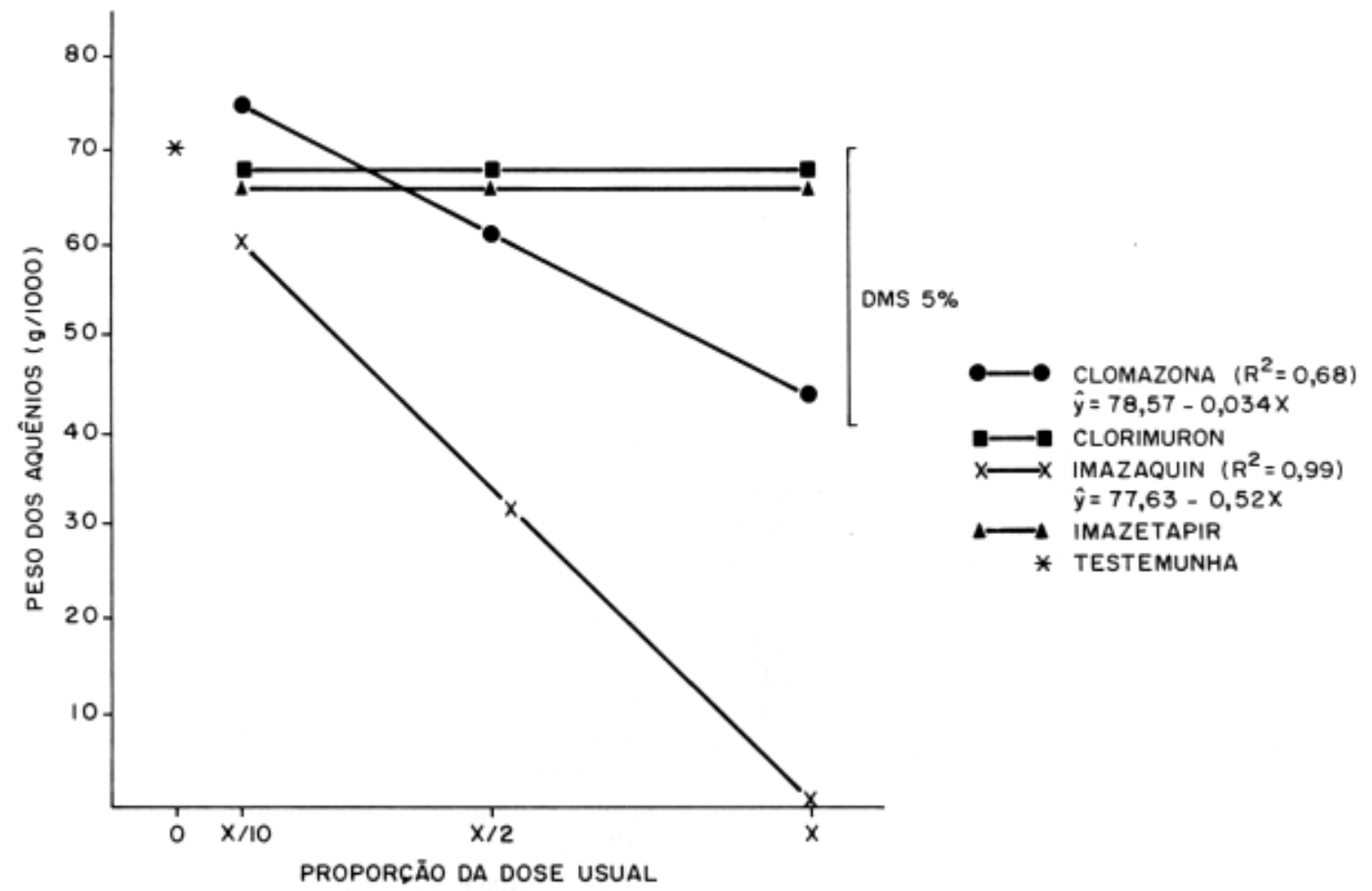

FIG. 3 - Peso de mil aquênios de girassol (g) na colheita, na média de duas épocas de aplicação, após aplicação ao solo dos herbicidas clomazone, chlorimuron-ethyl, imazaquin e imazethapyr, comparados à testemunha sem herbicidas. EEA/UFRS, Eldorado do Sul, RS, 1989/90. 


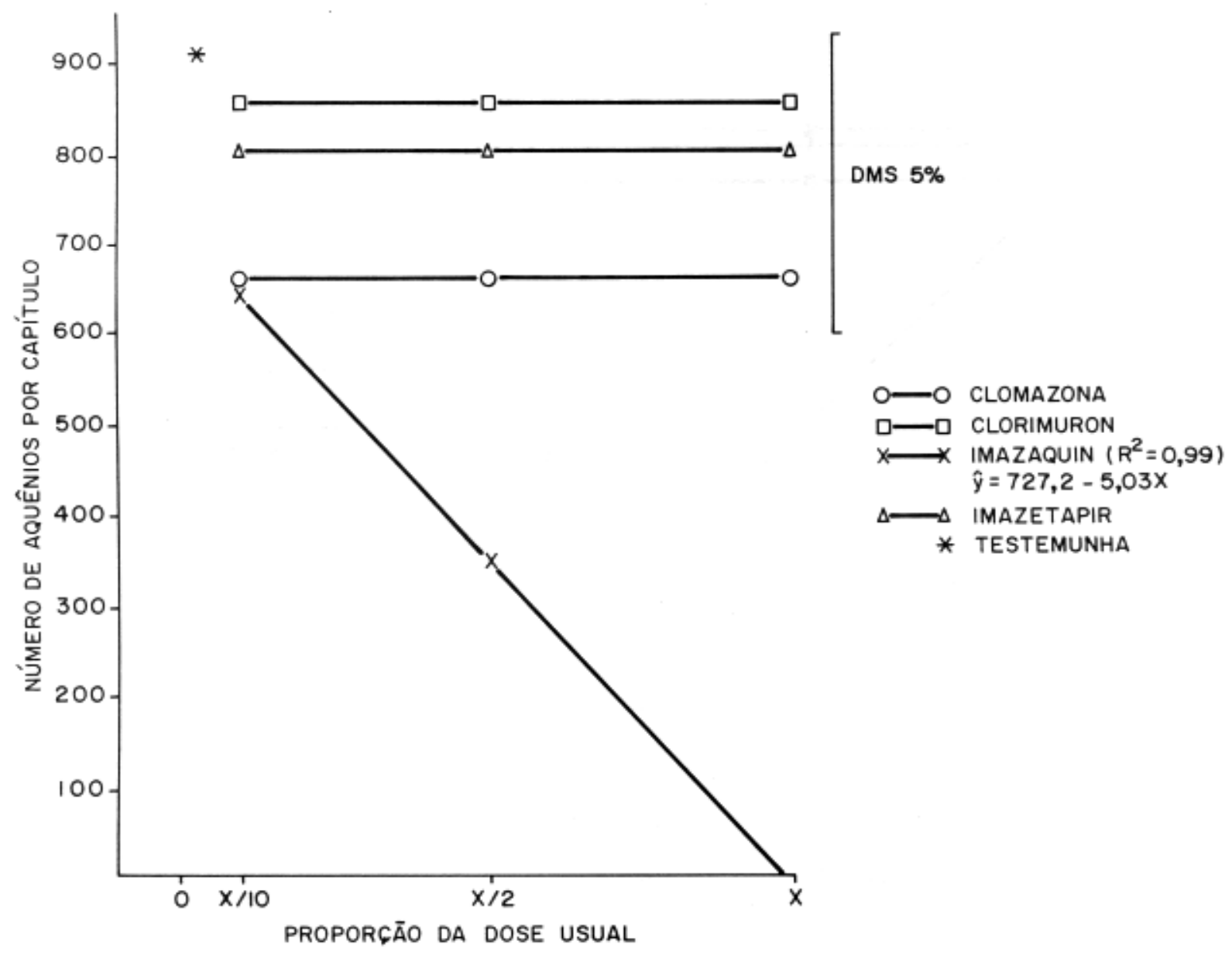

FIG. 4 - Número de aquênios por capítulo de girassol na colheita, na média de duas épocas de aplicação, após aplicaçảo ao solo dos herbicidas clomazone, chlorimuron-ethyl, imazaquin e imazethapyr, comparados à testemunha sem herbicidas. EEA/UFRS, Eldorado do Sul, RS, 1989/90.

dose de chlorimuron-ethyl não reduziu o rendimento em relação à testemunha. Contudo, com o incremento da dose deste produto, nesta época de aplicação, houve redução linear do rendimento. Por outro lado, quando chlorimuronethyl foi aplicado em PRE, ocorreu comportamento inverso, ou seja, constatou-se redução do rendimento em relação à testemunha, mesmo com a menor dose. Porém, não se observou resposta à variação da mesma.

$\mathrm{O}$ rendimento das plantas tratadas com a menor dose de imazethapyr e de clomazone não diferiu da testemunha. Contudo, com o incremento das doses destes herbicidas ocorreu redução linear no rendimento (Figura 5).

O herbicida imazaquin, mesmo na menor dose, promoveu redução significativa do rendimento. As plantas localizadas na área tratada com este produto apresentaram o menor valor. As tratadas com clomazone apresentaram rendimento intermediário em relação às tratadas com imazaquin e imazethapyr (Figura 5).

$\mathrm{Na}$ Tabela 1 apresentam-se as regressões entre o rendimento de aquênios e os componentes do mesmo. Observa-se que o peso médio do aquênio, tanto nas regressões múltiplas como nas simples, foi o fator que menos contribuiu para o rendimento final. Análises de cada componente indicaram que $80 \%$ da variação do rendimento foi determinado pela população de girassol, enquanto que 59, 49 e 53\% do mesmo foram determinados pelo número de aquênios por capítulo, peso médio do aquênio e diâmetro do capítulo, respectivamente. As regressões calculadas sugerem que o fator que mais influenciou no rendimento foi a variação de plantas sobreviventes na área.

De fato, a redução acentuada da população de girassol, com o incremento das doses dos herbicidas (Figura 1), influenciou todos os parâmetros avaliados nos estádios mais avançados de desenvolvimento da cultura, tais como: tamanho de capítulo, componentes do rendimento e rendimento de aquênios. Assim, os resultados relatados para estas variáveis se devem mais à ausência de plantas nas parcelas do que à redução daqueles parâmetros nos vegetais avaliados. $\mathrm{O}$ fato de um mesmo tratamento herbicida ter eliminado todas as plantas em algumas parcelas, mas não em todas, pode ser atribuído a características intrínsecas das sementes (Duke, 1985), a pequenas diferenças na profundidade de colocação das sementes ou ao efeito de microlocal (Duke, 1985), visto que a cultura semeada foi um híbrido, portanto com genótipo homogêneo. 


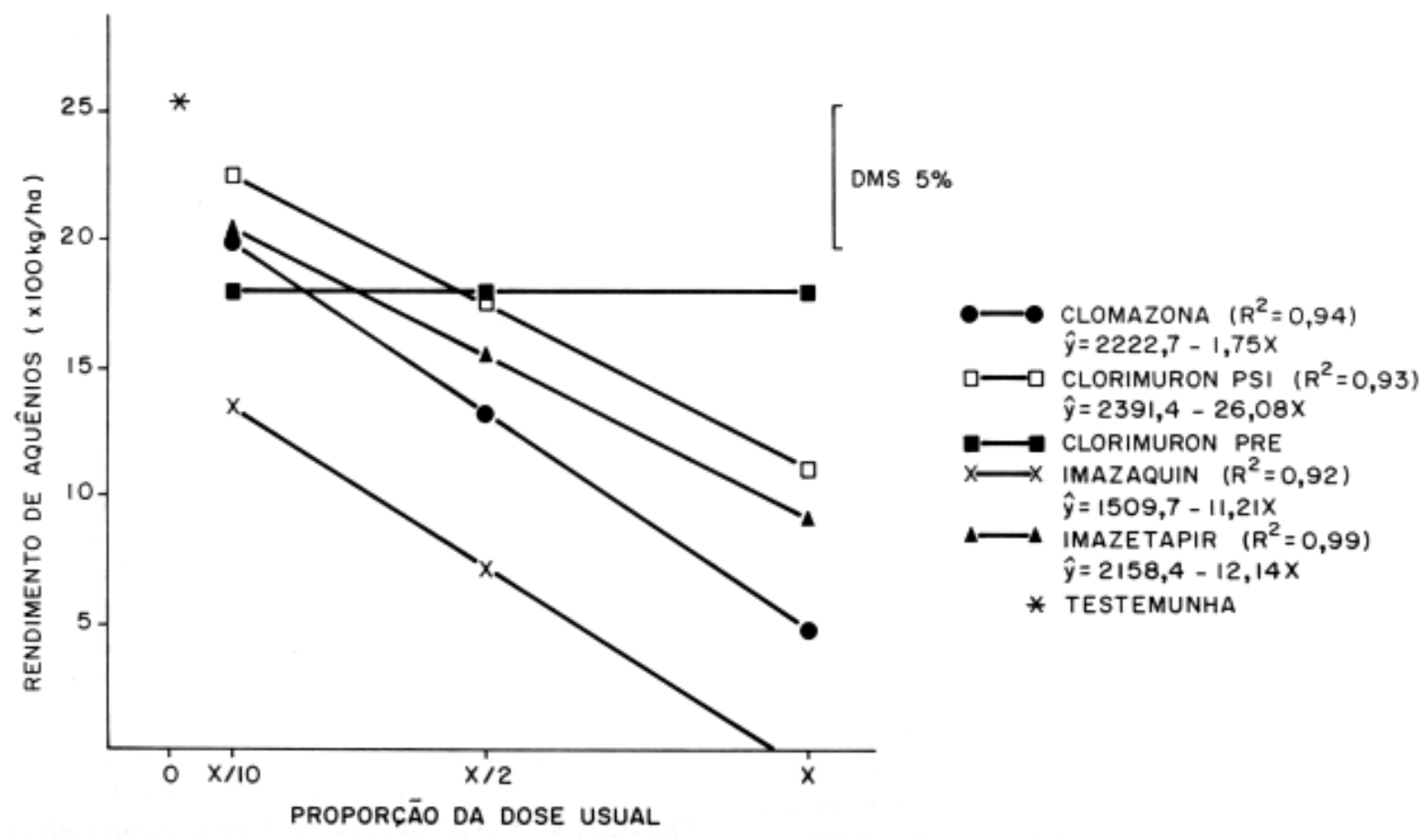

FIG. 5 - Rendimento de aquênios de girassol $(\mathrm{kg} / \mathrm{ha})$ na colheita, após aplicaçāo ao solo dos herbicidas clomazone, chlorimuron-ethyl, imazaquin e imazethapyr, comparados à testemunha sem herbicidas. EEA/UFRS, Eldorado do Sul, RS, 1989/90.

TABELA 1 - Equações de regressão entre rendimento de aquênios $(\mathrm{Y})$ e os componentes ${ }^{\mathrm{a}}$ do rendimento.EEA/UFRS, Eldorado do Sul, RS, $1989 / 90$.

\begin{tabular}{|c|c|}
\hline Equaçōes & $\mathbf{R}^{2}$ \\
\hline$-43,11+2,05 A^{*}-3,12 \mathrm{~B} N S+60,49 \mathrm{C}^{* *}+0,05 \mathrm{D}^{* *}$ & $0,93^{* *}$ \\
\hline$-61,72+1,67 A^{* *}-13,44 B^{* *}+0,045 D^{* *}$ & $0,92^{* *}$ \\
\hline$-64,97+5,68 \mathrm{~B}^{* *}+0,045 \mathrm{D}^{*}$ & $0,81^{\bullet \bullet}$ \\
\hline $121,96+1,80 \mathbf{A}^{* *}$ & $0,59^{* *}$ \\
\hline $91,11+21,08 \mathrm{~B}^{* *}$ & $0,49^{* *}$ \\
\hline $39,68+82,67 \mathrm{C}^{* *}$ & $0,53^{* *}$ \\
\hline $95,55+0,053 \mathrm{D}^{* *}$ & $0,80^{* *}$ \\
\hline
\end{tabular}

${ }^{a} \mathrm{n}=100$.

$\mathrm{R}^{2}=$ Coeficiente de determinação.

$A=$ Número de aquênios/capítulo.

$\mathrm{B}=$ Peso de 1000 aquênios $(\mathrm{g})$.

$\mathrm{C}=$ Diâmetro médio do capítulo $(\mathrm{cm})$.

$\mathrm{D}=$ Número de plantas/hectare.

NS = Nāo significativo $(P>0,05)$.

- = Significativo pelo teste $\mathrm{T}$, à $5 \%$ de probabilidade.

* = Significativo pelo teste T, à $1 \%$ de probabilidade.

Os herbicidas que reduziram mais intensamente a população e o rendimento de girassol foram imazaquin e clomazone (Figuras 1 e 5), não sendo encontrado efeito diferenciado com as épocas de aplicação. Resultados semelhantes foram obtidos por Halstead \& Harvey (1988) com o herbicida clomazone. Constataram redução acentuada do número de plantas de girassol semeado após a aplicação deste produto.
Outros autores também relataram incremento do rendimento com o aumento da população de girassol. Rizzardi (1991) obteve maiores rendimentos do híbrido DK-180 com populações de 30 a 50 mil plantas por hectare. Outros genótipos de girassol apresentraram incremento do rendimento quando se elevou a população até 50 mil (Schmidt, 1985) ou até 70 mil plantas por hectare (Nepomuceno, 1989).

A interação de épocas de aplicação e doses de chlorimuron-ethyl, tanto para avaliação da população como do rendimento (Figuras 1 e 5), pode ser atribuída a uma recuperação mais acentuada das plantas, quando o produto foi aplicado em PRE. Este resultado ocorreu porque, quando aplicado na superfície do solo, este produto ou foi menos absorvido, ou menos translocado, ou mais metabolizado, ou ocorreu mais de um destes processos (Duke, 1985).

Para avaliar o efeito residual potencial dos herbicidas testados procederam-se estimativas das meia-vidas necessárias para que sobrasse no solo resíduo suficiente para reduzir o rendimento em 50\%. A partir das equações da Figura 5 determinourse que as doses necessárias para $50 \%$ de redução do rendimento seriam $87,75,56$ e $15 \%$ da dose recomendada dos herbicidas chlorimuron-ethyl em PPI, imazethapyr, clomazone e imazaquin, respectivamente. Chlorimuron em PRE reduziu o rendimento em apenas 27\%. Admitindo-se um intervalo (t) de 210 dias (7 meses) entre a aplicação dos herbicidas e a semeadura do girassol, pode-se determinar a constante de degradação dos herbicidas (k), utilizando-se a equação (2):

$$
\operatorname{Ln}([\mathrm{Cf}] /[\mathrm{Ci}])=-\mathrm{kt}
$$

Esta equação, de acordo com Witt (1989), Beckie \& McKercher (1989) e Gallandt et al. (1989), representa a 
cinética de degradação de clomazone, chlorimuron-ethyl, imazaquin e imazethapyr no solo; onde [Ci] e [Cf] são as concentrações dos herbicidas no tempo inicial e final. Determinou-se que o valor -k corresponde a 0,00076; 0,0013; 0,0027 e 0,0090 para chlorimuron-ethyl em PPI, imazethapyr, clomazone e imazaquin, respectivamente. Utilizando-se, então, a equação (3):

$$
\mathrm{t} 1 / 2=0,693 / \mathrm{k}
$$

onde $t$ 1/2 representa a meia-vida do produto, estimou-se que as meia-vidas dos herbicidas para aquela redução no rendimento seriam de 1045, 505, 250 e 77 dias para chlorimuronethyl em PPI, imazethapyr, clomazone e imazaquin, respectivamente. No entanto, em trabalhos realizados nos Estados Unidos (Congleton et al., 1987; Renner et al., 1988; Witt, 1989; WSSA, 1989) verifica-se que apenas imazaquin apresenta meia-vida que poderia se enquadrar nas estimativas acima.

Os resultados deste experimento permitiram concluir que:

1. Os herbicidas clomazone, chlorimuron-ethyl, imazaquin e imazethapyr, utilizados na cultura da soja, potencialmente podem causar danos ao girassol cultivado em sucessão.

2. Os danos ocasionados ao girassol permitem classificar os herbicidas na seguinte ordem decrescente de redução no rendimento de aquênios: imazaquin > clomazone > imazethapyr > chlorimuron-ethyl.

3. O grau de dano promovido por chlorimuron - eth yl depende de seu modo de aplicação ao solo.

4. O efeito de dano mais pronunciado dos herbicidas foi a redução da população de plantas de girassol, a qual influenciou mais o rendimento de aquênios do que os outros componentes.

\section{AGRADECIMENTOS}

Ao Dr. João Riboldi, do Instituto de Matemática da UFRS, pelo apoio na análise estatística dos resultados.

\section{LITERATURA CITADA}

BECKIE, H. J.; MCKERCHER, R. B. Soil residual properties of DPX-A7881 under laboratory conditions. Weed Science, Champaign, v.37, p.412-418, 1989.

BREWSTER, B. D.; APPLEBY, A. P. Response of wheat (Triticum aestivum) and rotation crops to chlorsulfuron. Weed Science, Champaign, v.31, n.6, p.861$865,1983$.

CHEW, V. Comparing treatment means: a compendium. HortScience, Alexandria, v.11, n.4, p.348-357, 1976.

CONGLETON, W. F.; VANCANFORT, A. M.; LIGNOWSKI, E. M. Imazaquin (Scepter a new soybe an herbicide. Weed Technology, Champaign, v.2, p.186-188, 1987.
CURRAN, W. S.; KNAKE, E. L. Rotational crop injury potential for corn following clomazone, imazaquin, imazethapyr and chlorimuron in Illinois. In: MAINZ, M. J.; SUTOR, J. J. Northwestern Illinois Agricultural Research and Demonstration Center; report of research results. Urbana-Champaign: Univ. of Illinois, 1987. p.114-119.

DUKE, S. O. ed. Weed phy siology. Boca Raton: CRC, 1985. v.2, 25'7p.

EBERLEIN, C. V.; ROSOW, K. M.; GEADELMANN, J. L.; OPENSHAW, S. J. Differential tolerance of corn ge notypes to DPX-M63133. Weed Science, Champaign, v.37, p.651-657, 1989.

GALLANDT, E. R.; FAY, P. K.; INSKEEP, W. P. Clomazone dissipation in two Montana soils. Weed Technology, Champaign, v.3, p.146-150, 1989.

GRIFFIN, J. L.; BAKER, J. B. Tolerance of rice cultivars to fenoxaprop, se thoxydim, and haloxy fop. Weed Science, Champaign, v.38, p.528-531. 1990.

FLECK, N. G. Controle de plantas daninhas em gírassol: a escolha do herbicida a usar. Lavoura Arrozeira, Porto Alegre, v.43, n.391, p.11-13, 1990.

GOMEZ, K. A.; GOMEZ, A. O. Statistical procedures for agricultural research. 2.ed. New York: John Wiley, 1984. 680p.

HALSTE AD, S. J.; HAR VEY, R. G. Effect of rate and carrier on clomazone movement off-site. Weed Technology, Champaign, v.2, p.179-182, 1988.

NEPOMUCENO, A. L. Efeito do arranjo de plantas de girassol no controle de ervas daninhas e nas características de plantas associadas à colheita. Porto Alegre: UFRS - Fac. Agronomia, 1989. 84p. Dissertação de Mestrado.

NOGUEIRA, I. R. Método geral para obtenção de tabelas de polinômios ortogonais. Revista de Agricultura, Piracicaba, v.53, n.4, p.269-279, 1979.

PEI'ERSEN, R. G. Use and misuse of multiple comparison procedures. Agronomy Journal, Madison, v.69, p.205-208, 1977.

PETERSON, M. A.; ARNOLD, W. E. Response of rotational crops to soil residues of chlorsulfuron. Weed Science, Champaign, v.33, n.1, p.131-136, 1985.

RENNER, K. A.; MEGGITT, W. F.; LEAVITT, R. A. Influence of rate, method of application, and tillage on imazaquin persistence in soil. Weed Science, Champaign, v.36, p.90-95, 1988.

RIZZARDI, M. A. Resposta de cultivares de girassol à densidade de plantas, em duas épocas de semeadura. Porto Alegre: UFRS - Fac. Agronomia, 1991. 84p. Dissertação de Mestrado.

SCHMIDT, E. Efeito de densidade e do arranjo de plantas no rendimento de aquénios e óleo, e ern outras características agronômicas do girassol. Porto Alegre: UFRS - Fac. Agronomia, 1985. 97p. Dissertação de Mestrado.

SNIPES, C. E; STREET, J. E. Rice tolerance to fenoxaprop. Weed Science, Champaign, v.35, p.401-406, 1987. 
VIDAL, R. A. Impacto de herbicidas seletivos para a soja sobre plantas espontâneas e cultivadas de girassol. Porto Alegre: UFRS - Fac. Agronomia, 1990. 159p. Dissertação de Mestrado.

VIDAL, R. A.; FLECK, N. G. Injuria potencial de herbicidas de solo ao girassol. I- Clomazone. Planta Daninha, Brasília, v.11, n.1/2, p.36-43, 1993.

VRANCEANU, A. V. Tecnica del cultivo. In: VRANCEANU, A.V. El Girasol. Madrid: Mundi-Prensa, 1977. p.247-313.
WILKINS, H. D.; SWALLERS, C. Sunflower production in North Dakota. Fargo, N. Dakota State Univ-Coop. Ext. Serv., 1972. 9p. (Circular, A-538 rev.)

WITT, W. W. Persistence of imazaquin, imazethapyr, and clomazone in notill double-crop soybeans. In: CONFERENCIA MUNDIAL DE INVESTIGACION EN SOYA, 4., 1989, Buenos Aires. Actas ... Buenos Aires: J. A. Pascale, 1989. p.1683-1688.

WSSA. Herbicide handbook. 6.ed. Champaign: WSSA, 1989. 301p. 